\title{
Efeito de dietas com níveis crescentes de caroço de algodão integral sobre a composição química e o perfil de ácidos graxos da carne de cordeiros Santa Inês
}

\author{
Marta Suely Madruga ${ }^{1}$, Thereza Raquel de Lucena Vieira ${ }^{2}$, Maria das Graças Gomes Cunha ${ }^{3}$, \\ José Morais Pereira Filho ${ }^{4}$, Rita de Cássia Ramos do Egypto Queiroga ${ }^{5}$, Wandrick Hauss \\ de Sousa ${ }^{3}$ \\ ${ }^{1}$ Departamento de Tecnologia Química e de Alimentos, Universidade Federal da Paraíba (DTQA/UFPB), Campus I, João Pessoa-PB, \\ CEP: $59.059-900$ \\ 2 Programa de Pós-graduação em Ciência e Tecnologia de Alimentos (PPGCTA/DTQA/UFPB). \\ ${ }^{3}$ Empresa Estadual de Pesquisa Agropecuária da Paraíba - EMEPA. Rua Eurípides Tavares, n. 210, Tambiá, João Pessoa-PB, \\ CEP: $58.013-290$ \\ ${ }^{4}$ Departamento de Medicina Veterinária, Centro de Saúde e Tecnologia Rural da Universidade Federal da Paraíba, Caixa Postal 64, Jatobá, \\ CEP: 58.708-110, Patos-PB \\ ${ }^{5}$ Departamento de Nutrição, Universidade Federal da Paraíba (DN/UFPB), Campus I, João Pessoa-PB, CEP: 59.059-900.
}

RESUMO - Esta pesquisa foi realizada com o objetivo de avaliar o efeito da inclusão (0, 20, 30 e 40\%) de caroço de algodão integral (Gossypium hirsutum) na dieta sobre a composição química e o perfil de ácidos graxos da carne de cordeiros Santa Inês. Foram utilizados 24 cordeiros machos não-castrados (peso corporal inicial de 19,0 \pm 0,2 kg e 4 meses de idade), todos criados em regime de confinamento em baias individuais. Os níveis de caroço de algodão integral não afetaram a composição centesimal e os percentuais de colesterol e fosfolipídios da carne ovina. Entretanto, houve diferença entre os percentuais dos ácidos graxos mirístico, palmítico e linolênico e entre a relação C18:0 + C18:1 / C16:0. Do ponto de vista nutricional, a utilização de caroço de algodão integral na dieta pode ser recomendada, durante períodos curtos, em níveis de até $40 \%$ para ovinos em terminação. Ressalta-se que o caroço de algodão integral é um subproduto economicamente viável por apresentar baixo custo de produção em comparação ao milho e à soja.

Palavras-chave: alimentação, carne ovina, colesterol, fosfolipídios, perfil lipídico, proteína

\section{Effect of diets with increasing levels of whole cotton seed on chemical composition and fatty acid profile of Santa Inez (Santa Inês) lamb meat}

ABSTRACT - The objective of this research was to evaluate the effect of inclusion $(0,20,30$ and $40 \%)$ of whole cottonseed (Gossypium hirsutum) in the diet on chemical composition and fatty acids profile of Santa Inez sheep meat. Twenty four no castrated male sheep were used, (initial $19.0 \pm 0.2 \mathrm{~kg}$ BW and 4 month old), all kept in confinement regime in individual stalls. The levels of whole cottonseed did not affect chemical composition and the percentages of cholesterol and phospholipids of the lamb meat. However, there was difference among the percentages of the miristic, palmitic and linolenic fatty acids and also to the relationship C18:0 + C18:1 / C16:0. At nutritional point of view, the utilization of whole cottonseed could be recommended, during short periods, up to the level of $40 \%$ for finishing animals. In addition, whole cottonseed is a by-product economically viable for presenting low production cost as compared to corn and soybean.

Key Words: cholesterol, fat profile, feeding, lamb meat, phospholipids, protein

\section{Introdução}

A produção de carne ovina tem aumentado significativamente, como resultado do elevado potencial do mercado consumidor dos grandes centros urbanos brasileiros, e apresenta-se como uma atividade alternativa capaz de adicionar renda aos negócios, não só dos ovinocultores, mas à atividade rural como um todo, independentemente de se ter tradição na criação de ovinos (Silva Sobrinho, 2001).

A raça Santa Inês - desenvolvida a partir de animais deslanados objetivando a produção de carne - é exigente quando se buscam altos níveis de produtividade (Souza et al., 2003). Raças ou animais de elevada produtividade apresentam também grandes exigências nutricionais. O 
músculo e a carne produzidos por um animal resultam da alimentação; então, para se produzir muito em pouco tempo, é necessário não apenas o potencial genético, mas também o fornecimento de dietas com níveis nutricionais adequados. A alimentação dos animais é um dos fatores que mais influenciam a atividade de ovinocultura na Região Nordeste do Brasil, uma região com longos períodos de estiagem que reduzem a oferta de pastagens, limitando, segundo Marques et al. (2007), a expressão do potencial genético de ovinos e de outros animais. O confinamento de ovinos é uma alternativa para reduzir a pressão de pastejo na caatinga, pois diminui a idade ao abate e possibilita maior ganho de peso (Barros et al., 2003), principalmente nas regiões com potencial de utilização de resíduos e subprodutos agropecuários, como aqueles resultantes da produção de acerola, melão, maracujá, goiaba (Lousada Jr.et al., 2005), abacaxi (Correia et al., 2006), e restolhos de cultura (Pereira Filho \& Vieira, 2006).

Coppock et al. (1985) relataram que a semente de algodão integral é um alimento com altos teores de lipídios, proteínas e fibra bruta e sua utilização na alimentação de ruminantes têm recebido atenção crescente de pesquisadores, principalmente em virtude de seus altos teores de lipídios, que possibilitam elevar a densidade energética das dietas sem diminuir os teores de fibra e proteínas. Beaudoin (1985) comenta, no entanto, que a qualidade nutricional da semente de algodão é limitada pela presença de gossipol, um pigmento amarelo natural, que pode causar em animais não-ruminantes anormalidade nas organelas celulares e interferir nos processos bioquímicos, pois inibe a atividade de várias enzimas.

De acordo com Harris et al. (1993), a atenção do consumidor à relação entre dieta e saúde tem resultado na crescente preocupação com o conteúdo de gordura e colesterol dos produtos de origem animal. Recomenda-se redução da ingestão de gorduras ricas em colesterol e ácidos graxos saturados e aumento do consumo de ácidos graxos mono e poliinsaturados com o propósito de diminuir o risco de obesidade, câncer e doenças cardiovasculares (Jakobsen, 1999).

Apesar da literatura sobre o efeito da alimentação nas características da carcaça e da carne de cordeiros, poucos dados estão disponíveis sobre utilização de subprodutos de indústrias locais na alimentação de ovinos e seus efeitos na qualidade química da carne de cordeiros Santa Inês. Assim, objetivou-se neste estudo analisar o efeito da inclusão de níveis crescentes de caroço de algodão integral (Gossypium hirsutum) na dieta sobre os componentes químicos e o perfil lipídico da carne de ovinos da raça Santa Inês.

\section{Material e Métodos}

Foram utilizados 24 cordeiros Santa Inês, machos nãocastrados com peso corporal (PC) médio inicial de 19,0 \pm 0,2 kg e 4 meses de idade, distribuídos ao acaso nos tratamentos (níveis de caroço de algodão integral) experimentais, com seis repetições. Os animais foram submetidos a um período experimental de 70 dias, precedido de 14 dias para adaptação ao manejo e às dietas. Os cordeiros foram pesados no início do estudo e a cada 14 dias para acompanhamento do desenvolvimento ponderal e ajustes no fornecimento da dieta.

As dietas foram formuladas de acordo com recomendações do NRC (1981) e compostas de palma forrageira, feno de capim-tifton, milho triturado, farelo de soja, uréia e minerais e contendo quatro níveis $(0,20,30$ e $40 \%)$ de caroço de algodão integral para atender às exigências de proteína e energia metabolizável dos animais para mantença e ganho de peso diário de $200 \mathrm{~g}$ (Tabela 1).

Ao atingir 70 dias de idade, após jejum de sólidos por 24 horas e jejum hídrico por 16 horas, os animais foram pesados para obtenção do peso corporal final. Em seguida, foram abatidos segundo normas vigentes do RIISPOA (BRASIL, 1997). As carcaças foram resfriadas em câmara frigorífica com temperatura inferior a $5^{\circ} \mathrm{C} \pm 2^{\circ} \mathrm{C}$ por 24 horas.

Decorridas 24 horas pos-mortem, os músculos Semimembranosus (do lado esquerdo da carcaça) foram retirados, identificados, embalados em sacos plásticos e armazenados em freezer $\left(-18^{\circ} \mathrm{C}\right)$ por um período não superior a dois meses até as análises químicas. Ao início das análises químicas, os músculos foram descongelados em geladeira convencional por 24 horas. Em seguida, realizaram-se a toalete, com retirada da gordura de cobertura, e a trituração em liquidificador doméstico até obtenção de uma pasta homogênea.

Os teores de umidade, cinzas e proteínas foram quantificados segundo metodologia descrita pela AOAC (2000). A gordura foi extraída pelo método de Folch et al. (1957). As determinações dos componentes lipídicos constaram, além do cálculo dos lipídios totais, da determinação do colesterol total (Bohac et al., 1988) e dos teores de fosfolipídios totais (Egan et al., 1981) e do perfil de ácidos graxos saturados, mono e poliinsaturados (Madruga et al., 2006).

Os dados obtidos foram analisados estatisticamente por meio de análise de variância (ANOVA) pelo programa estatístico Statistical Analysis System (SAS), versão 6.12 (SAS, 1996), em delineamento inteiramente casualizado, com quatro dietas e seis repetições. Na análise de variância, aplicaram-se o teste F a 5\% de significância e o teste de Tukey a 5\% de probabilidade. 
Tabela 1 - Composição percentual (\% MS) e química ( $\mathrm{g} / \mathrm{kg})$ das dietas experimentais

\begin{tabular}{|c|c|c|c|c|}
\hline \multirow[b]{2}{*}{ Ingrediente (\%) } & \multicolumn{4}{|c|}{$\begin{array}{l}\text { Nível de caroço de } \\
\text { algodão integral (\%) }\end{array}$} \\
\hline & 0 & 20 & 30 & 40 \\
\hline Feno de capim-tifton & 33,1 & 30,5 & 36,6 & 31,2 \\
\hline Milho triturado & 32,6 & 21,6 & 6,4 & 0,0 \\
\hline Farelo de soja & 7,8 & 0,0 & 0,0 & 0,0 \\
\hline Palma forrageira & 24,4 & 25,0 & 25,2 & 25,8 \\
\hline Uréia & 1,1 & 1,0 & 0,8 & 0,5 \\
\hline Mistura mineral & 0,5 & 0,5 & 0,5 & 0,5 \\
\hline Calcário calcítico & 0,5 & 1,4 & 0,5 & 2,0 \\
\hline Caroço de algodão integral & 0,0 & 20,0 & 30,0 & 40,0 \\
\hline \multicolumn{5}{|l|}{ Composição química (g/kg) } \\
\hline Matéria seca & 723,0 & 722,0 & 723,0 & 721,0 \\
\hline Proteína bruta & 150,0 & 150,0 & 159,0 & 167,0 \\
\hline Matéria mineral & 69,0 & 74,0 & 66,0 & 81,0 \\
\hline Matéria orgânica & 931,0 & 926,0 & 934,0 & 919,0 \\
\hline Extrato etéreo & 29,0 & 60,0 & 74,0 & 90,0 \\
\hline Fibra detergente neutro & 364,0 & 416,0 & 496,0 & 496,0 \\
\hline $\begin{array}{l}\text { Fibra detergente neutro } \\
\text { corrigida para proteína }\end{array}$ & 342,0 & 393,0 & 469,0 & 468,0 \\
\hline Carboidratos totais & 752,0 & 716,0 & 701,0 & 662,0 \\
\hline Carboidratos não-fibrosos & 410,0 & 323,0 & 232,0 & 194,0 \\
\hline Fibra em detergente ácido & 198,0 & 249,0 & 301,0 & 317,0 \\
\hline $\begin{array}{l}\text { Energia metabolizável } \\
\text { (kcal/kg MS) }\end{array}$ & $4.300,0$ & $4.400,0$ & $4.500,0$ & $4.800,0$ \\
\hline $\begin{array}{l}\text { Nutrientes digestíveis } \\
\text { totais }\end{array}$ & 622,0 & 610,0 & 620,0 & 632,0 \\
\hline
\end{tabular}

\section{Resultados e Discussão}

Diferenças significativas $(\mathrm{P}<0,05)$ foram observadas para o ganho de peso total (GPT) e o ganho de peso médio diário (GPMD) entre o grupo controle ( $0 \%$ ) e aqueles alimentados com dieta com $30 \%$ de caroço de algodão integral (Tabela 2). Os animais que não receberam caroço de algodão apresentaram maiores ganho de peso total e ganho de peso médio diário e aqueles alimentados com as dietas com 20 e 40\% de caroço de algodão apresentaram ganhos intermediários e semelhantes aos obtidos com os demais níveis de caroço de algodão integral.

A composição centesimal e os teores de colesterol e fosfolipídios da carne ovina não foram influenciados $(\mathrm{P}>0,05)$ pelos níveis de caroço de algodão integral da dieta (Tabela 2). A ausência de diferenças significativas para os parâmetros químicos da carne ovina, especialmente os teores de lipídios e colesterol, provavelmente foi ocasionada pelo curto período de confinamento (70 dias) e pelos pesos de abate, que variaram de 33,5 a 30,41 kg e não foram suficientes para ocasionar deposição de gordura, especialmente intramuscular (marmoreio), comprovando que os cordeiros não atingiram a maturidade fisiológica. Segundo Ely et al. (1979), dietas ricas em concentrados aumentam os teores de gordura na carcaça de cordeiros 3/4 Suffolk + 1/4 Rambouillet abatidos com peso médio de 49,9 kg. Segundo Bonagurio et al. (2004), cordeiros Santa Inês abatidos aos $15 \mathrm{~kg}$ apresentaram maior teor de umidade e maior quantidade de músculo em comparação aos animais abatidos com $45 \mathrm{~kg}$, que possuíam mais gordura.

Zundt et al. (2002) enfatizaram que ovinos em confinamento apresentam maior velocidade de ganho de peso e que, dependendo da raça, podem atingir $30 \mathrm{~kg}$ PC antes dos 5 meses de idade, o que foi comprovado pelos autores em animais "tricross" (1/2 Texel + 1/4 Bergamácia + $1 / 4$ Corriedale). Sousa \& Espíndola (1999), no entanto, em experimento com ovinos Morada Nova em pastagens de capim-buffel (Cenchrus ciliari.); capim-buffel + guandu (Cajanus cajan); e capim-buffel + leucena (Leucaena leucocephala), reportaram que, ao final de 365 dias idade nenhum animal atingiu $30 \mathrm{~kg}$ PC. Entretanto, considerando que em várias regiões do Brasil os consumidores preferem ovinos com carcaças mais pesadas, recomenda-se a terminação em confinamento, que evita o abate de ovinos em idade mais avançada, cuja carne é menos macia.

A composição centesimal da carne de cordeiros Santa Inês nesta pesquisa corrobora a descrita em pesquisas com carne de cordeiros Santa Inês alimentados com diversos volumosos - feno de capim-d'água, feno de restolho de abacaxi, palma e silagem de milho (Madruga et al., 2005) e com cordeiros Apennine alimentados com três diferentes fontes energéticas contendo concentrado com óleo de milho e feno (Russo et al., 1999). Zeola et al. (2004), no entanto, verificaram que os níveis de concentrado influenciaram $(\mathrm{P}<0,05)$ os percentuais de proteínas do músculo Semimembranosus da carne de cordeiros Morada Nova alimentados com três dietas com diversos níveis de concentrado. Rowe et al. (1999) observaram maior deposição de gordura (10,79\%) no músculo Longissimus dorsi de cordeiros alimentados com dieta concentrada em comparação àqueles mantidos em pastagem, que apresentaram $6,85 \%$ de gordura na carne.

Em termos absolutos, observou-se decréscimo do teor de colesterol à medida que o caroço de algodão foi adicionado à dieta. Os valores médios de colesterol da carne ovina variaram de $80,60 \mathrm{mg} / 100 \mathrm{~g}$ nos animais que receberam a dieta controle a 77,96 mg/100 g nos animais alimentados com $40 \%$ de caroço de algodão integral. Considerando que o valor de colesterol encontrado é considerado baixo ( $<90 \mathrm{mg} / 100 \mathrm{~g}$ ), estes resultados permitem que os criadores de ovinos explorem a qualidade nutricional da carne ovina de Santa Inês como um produto saudável. Consumidores 
Tabela 2 - Produção e composição química da carne de cordeiros Santa Inês alimentados com dietas contendo caroço de algodão integral

\begin{tabular}{lrrrr}
\hline & \multicolumn{4}{c}{ Caroço de algodão integral na dieta $(\%)^{1}$} \\
\cline { 2 - 5 } & \multicolumn{1}{c}{0} & 20 & 30 & 40 \\
\hline Peso vivo inicial (kg) & $19,10 \pm 0,84 \mathrm{a}$ & $19,61 \pm 1,58 \mathrm{a}$ & $19,96 \pm 1,28 \mathrm{a}$ & $19,96 \pm 1,23 \mathrm{a}$ \\
Peso vivo final (kg) & $33,50 \pm 1,73 \mathrm{a}$ & $32,66 \pm 2,60 \mathrm{a}$ & $30,41 \pm 2,15 \mathrm{a}$ & $32,16 \pm 1,40 \mathrm{a}$ \\
Ganho peso total (kg) & $14,40 \pm 1,46 \mathrm{a}$ & $13,05 \pm 1,68 \mathrm{ab}$ & $10,45 \pm 1,65 \mathrm{~b}$ & $12,20 \pm 1,17 \mathrm{ab}$ \\
Ganho peso médio diário (g) & $205 \pm 0,02 \mathrm{a}$ & $186 \pm 0,02 \mathrm{ab}$ & $149 \pm 0,02 \mathrm{~b}$ & $174 \pm 0,01 \mathrm{ab}$ \\
Umidade (g/100 g) & $72,48 \pm 0,48 \mathrm{a}$ & $72,50 \pm 0,39 \mathrm{a}$ & $73,21 \pm 0,32 \mathrm{a}$ & $72,96 \pm 0,16 \mathrm{a}$ \\
Cinzas (g/100g) & $0,94 \pm 0,03 \mathrm{a}$ & $1,03 \pm 0,03 \mathrm{a}$ & $1,02 \pm 0,03 \mathrm{a}$ & $1,06 \pm 0,04 \mathrm{a}$ \\
Proteínas (g/100 g) & $23,44 \pm 0,24 \mathrm{a}$ & $24,17 \pm 0,30 \mathrm{a}$ & $23,26 \pm 0,53 \mathrm{a}$ & $23,61 \pm 0,23 \mathrm{a}$ \\
Lipídios (g/100 g) & $3,41 \pm 0,25 \mathrm{a}$ & $3,91 \pm 0,23 \mathrm{a}$ & $3,68 \pm 0,22 \mathrm{a}$ & $3,59 \pm 0,25 \mathrm{a}$ \\
Colesterol (mg/100 g) & $80,60 \pm 6,17 \mathrm{a}$ & $80,38 \pm 1,40 \mathrm{a}$ & $79,85 \pm 8,21 \mathrm{a}$ & $77,96 \pm 4,06 \mathrm{a}$ \\
Fosfolipídios (mg/100 g) & $4,74 \pm 0,82 \mathrm{a}$ & $4,78 \pm 0,76 \mathrm{a}$ & $6,15 \pm 0,60 \mathrm{a}$ & $4,48 \pm 0,70 \mathrm{a}$ \\
\hline
\end{tabular}

${ }_{1}^{1}$ Médias seguidas de letras diferentes nas linhas, diferem $(P<0,05)$ significativamente pelo teste Tukey.

2 Coeficiente de variação (\%).

que ponderam o consumo de carnes vermelhas, tendo em vista o teor de colesterol de suas dietas, poderão aumentar o consumo de carne ovina de Santa Inês.

Os resultados para o colesterol da carne ovina estão próximos aos percentuais de colesterol do músculo Longissimus dorsi de ovinos Santa Inês e Bergamácia abatidos com faixa de peso de 15 a $45 \mathrm{~kg}$ (Perez et al., 2002), e aos de Suffolk $\times$ Hampshire abatidos com $50 \mathrm{~kg}$ (Solomon et al., 1992). No entanto, resultados inferiores aos desta pesquisa foram observados por Madruga et al. (2005) em carne de cordeiros Santa Inês terminados com diferentes dietas e abatidos com peso médio de 29 a 17 kg; por Zapata et al. (2001) em carne de cordeiros $1 / 2$ Somalis Brasileira $\times 1 \frac{1}{2}$ Crioula e $1 \frac{1}{2}$ Santa inês e $1 \frac{1}{2}$ Crioula; por Lough et al. (1992) em carne de cordeiros das raças Suffolk e Hampshire abatidos em média com 52 kg; por Monteiro \& Shimokomaki (1999) em carne de cordeiros Corriedale e Corriedale $\times$ Ile de France abatidos com 33,08 kg e 26,42 kg.

Valores inferiores aos encontrados nesta pesquisa foram relatados por Rowe (1998), avaliando a composição química do tecido adiposo de cordeiros Corriedale, mestiços Bergamácia $\times$ Corriedale e Hampshire Down $\times$ Corriedale terminados em pastagem e em confinamento. Esses autores encontraram níveis de colesterol nos animais terminados em pasto iguais a $62,03 \mathrm{mg} / 100 \mathrm{~g}$ e nos animais terminados em confinamento iguais a $57,76 \mathrm{mg} / 100 \mathrm{~g}$.

Os valores de fosfolipídios obtidos foram inferiores $(4,48$ a 6,15 mg/100 g) aos reportados por Madruga et al. (2005) em carne de cordeiros Santa Inês (13,39 a 21,67 mg/100 g) abatidos com $30 \mathrm{~kg}$ após terminação com dietas contendo diferentes fontes protéicas. Ressalta-se que, na literatura consultada, poucos trabalhos reportaram os teores de fosfolipídios da carne ovina, mesmo sabendo-se que os fosfolipídios, por serem formados na sua estrutura por ácidos graxos insaturados, apresentam grande efeito no processo de oxidação das carnes em geral, a exemplo das carnes bovina, suína, ovina e caprina.

No perfil dos ácidos graxos da carne de cordeiros Santa Inês, foram identificados 12 ácidos graxos, que representam a soma dos ácidos graxos presentes nos fosfolipídios e na fração lipídica neutra, compostos por triacilglicerídeos e por quantidades pequenas de ácidos graxos livres (Tabela 3).

Em termos absolutos, o percentual total dos AGS no músculo Semimembranosus de ovinos Santa Inês aumentou à medida que se adicionou o caroço de algodão integral à dieta dos ovinos; para o teor dos AGMI, a probabilidade foi inversa. O percentual total dos AGPI, em termos absolutos, foi maior $(13,54 \%)$ nos animais do grupo que recebeu dieta contendo $30 \%$ de caroço de algodão integral e, o menor percentual (10,4\%), no grupo controle ( $0 \%$ de caroço de algodão integral). Os resultados apresentados neste trabalho com relação aos percentuais totais de ácidos graxos poliinsaturados foram superiores aos encontrados por Tshabalala et al. (2005) em carne de ovinos Dorper e Damara da África do Sul (3,3 a 3,9), porém, semelhantes aos percentuais totais de ácidos graxos saturados e monoinsaturados. Percentuais semelhantes de AGS, AGM e AGPI foram obtidos por Madruga et al. (2005) em carne de cordeiros Santa Inês terminados em diferentes dietas.

O ácido graxo presente em maior área foi o ácido oléico, seguido dos ácidos palmítico, esteárico e linoléico. Esses resultados se assemelham aos reportados por Madruga et al. (2005), que encontraram a maior porcentagem de área para estes quatro ácidos em carne de cordeiros Santa Inês alimentados com diferentes dietas. Monteiro \& Shimokomaki (1999) encontraram dados semelhantes quando compararam o perfil de ácidos graxos no Longissimus dorsi de cordeiros resultantes do cruzamento entre as raças Ile de France × Corriedale e cordeiros Corriedale. 
Observaram-se diferenças $(\mathrm{P}<0,05)$ para os percentuais dos ácidos graxos saturados mirístico, palmítico e para o ácido graxo poliinsaturado linolênico. Madruga et al. (2005) encontraram valores médios de ácido mirístico, variando de 22,08 a $24,80 \%$, ao estudarem a qualidade da carne de cordeiros Santa Inês terminados com diferentes dietas. No entanto, os valores médios do ácido mirístico foram inferiores aos observados por Perez et al. (2002) em cordeiros Santa Inês e Bergamácia abatidos com diferentes pesos.

O grupo dos animais que receberam a dieta adicionada de $30 \%$ de caroço de algodão integral foi o grupo que apresentou maior concentração do ácido palmítico e provavelmente aquele com níveis séricos de colesterol mais elevados, uma vez que este ácido é o principal responsável pela elevação do colesterol sérico (Banskalieva et al., 2000).

Os teores de ácido graxo linoléico (C18:2) variaram de $10,40 \%$ (grupo controle) a 13,41\% (grupo da dieta adicionada de $30 \%$ de caroço de algodão integral), e não foram influenciados $(\mathrm{P}>0,05)$ pela inclusão do caroço de algodão integral. Wood et al. (2003) verificaram que músculos com elevados níveis de C18:2 (linoléico) oxidam rapidamente quando aquecidos, produzindo vários compostos voláteis, incluindo os aldeídos pentanal e hexanal, que comprometem a qualidade aromática da carne. A propriedade dos ácidos graxos insaturados, especialmente aqueles com número superior a duas duplas ligações, de oxidar-se mais rapida- mente, constitui um importante regulador da vida útil ou de prateleira da carne.

Os valores de ácido linolênico (C18:3) encontrados foram inferiores aos obtidos por Madruga et al. (2005) e Perez et al. (2002) em carne de ovinos Santa Inês, cujos percentuais variaram de 0,33 a 1,32\%. Bressan et al. (2004) citaram que o ácido graxo linolênico (C18:3), é considerado essencial, pois é o precursor para a síntese de muitos ácidos graxos poliinsaturados (AGPI). Esses autores enfatizaram que, embora os AGPI, em sua maioria, não sejam essenciais, eles desempenham um papel importante na diminuição do colesterol no sangue. Essas informações são confirmadas por outros autores na literatura, que relataram baixa ocorrência de doenças cardíacas, apesar de alto consumo de gorduras, em países do Mediterrâneo, onde ocorre o uso difuso de óleo de oliva e produtos similares, que proporcionam substancial absorção de ácidos graxos monoinsaturados, principalmente do ácido oléico (Wood et al., 1999). Como resultado desta dieta rica em óleo de oliva, ficou demonstrada a ocorrência de uma diminuição de colesterol no sangue comparável àquela de dietas pobres em gorduras (Wood et al., 1999).

Apenas a relação (C18:0 + C18:1)/C:16:0 diferiu $(\mathrm{P}<0,05)$ ente os níveis de caroço de algodão integral utilizados na dieta. Banskalieva et al. (2000) e Rhee et al. (1992) argumentaram que esta relação descreve os possíveis efeitos bené-

Tabela 3 - Perfil de ácidos graxos da carne de cordeiros Santa Inês terminados com diferentes níveis de caroço de algodão integral

\begin{tabular}{|c|c|c|c|c|c|}
\hline \multirow[t]{2}{*}{ Ácido graxo } & \multicolumn{5}{|c|}{ Caroço de algodão integral na dieta $(\%)^{1}$} \\
\hline & & 0 & 20 & 30 & 40 \\
\hline Saturados & 48,77 & $\pm 2,63 a$ & $50,42 \pm 5,39 a$ & $50,59 \pm 1,14 \mathrm{a}$ & $55,45 \pm 4,41 a$ \\
\hline C6:0 (Capróico) & 0,70 & $\pm 0,19 a$ & $0,52 \pm 0,17 a$ & $0,00 \pm 0,00 a$ & $0,35 \pm 0,21 a$ \\
\hline C8:0 (Caprílico) & 1,79 & $\pm 1,03 \mathrm{a}$ & $0,69 \pm 0,17 a$ & $0,00 \pm 0,00 a$ & $0,65 \pm 0,25 a$ \\
\hline C10:0 (Cáprico) & 0,00 & $\pm 0,00 \mathrm{a}$ & $0,14 \pm 0,05 a$ & $0,00 \pm 0,00 a$ & $0,32 \pm 0,19 a$ \\
\hline C12:0 (Láurico) & 0,00 & $\pm 0,00 \mathrm{a}$ & $0,87 \pm 0,37 a$ & $0,03 \pm 0,03 a$ & $0,59 \pm 0,37 a$ \\
\hline C14:0 (Mirístico) & 1,51 & $\pm 0,23 a$ & $1,15 \pm 0,40 \mathrm{ab}$ & $0,31 \pm 0,31 b$ & $1,86 \pm 0,25 a$ \\
\hline C16:0 (Palmítico) & 20,20 & $\pm 2,38 \mathrm{ab}$ & $16,57 \pm 2,92 b$ & $26,91 \pm 1,48 a$ & $25,16 \pm 1,93 a b$ \\
\hline C18:0 (Esteárico) & 18,38 & $\pm 4,82 \mathrm{a}$ & $25,83 \pm 7,18 a$ & $20,45 \pm 2,25 a$ & $23,24 \pm 4,47 a$ \\
\hline C20:0 (Araquídico) & 6,17 & $\pm 1,05 \mathrm{a}$ & $4,62 \pm 1,30 a$ & $2,87 \pm 2,75 a$ & $3,24 \pm 1,96 a$ \\
\hline Monoinsaturados & 40,82 & $\pm 3,85 a$ & $38,08 \pm 6,57 a$ & $35,86 \pm 0,91 \mathrm{a}$ & $32,86 \pm 2,64 a$ \\
\hline C16:1 (Palmitoléico) & 1,37 & $\pm 0,44 \mathrm{a}$ & $0,68 \pm 0,35 a$ & $0,17 \pm 0,17 a$ & $4,48 \pm 3,25 a$ \\
\hline C18:1 (Oléico) & 39,44 & $\pm 3,48 a$ & $37,40 \pm 6,26 a$ & $35,69 \pm 0,88 a$ & $28,38 \pm 5,55 a$ \\
\hline Poliinsaturados & 10,40 & $\pm 1,34 \mathrm{a}$ & $11,49 \pm 2,24 a$ & $13,54 \pm 0,63 a$ & $11,68 \pm 2,27 a$ \\
\hline C18:2 (Linoléico) & 10,40 & $\pm 1,34 \mathrm{a}$ & $11,28 \pm 2,32 \mathrm{a}$ & $13,41 \pm 0,67 a$ & $11,02 \pm 2,30 \mathrm{a}$ \\
\hline C18:3 (Linolênico) & 0,00 & $\pm 0,00 \mathrm{~b}$ & $0,20 \pm 0,13 b$ & $0,12 \pm 0,12 b$ & $0,66 \pm 0,10 a$ \\
\hline C18:0+C18:1/C16:0 & 3,17 & $\pm 0,68 \mathrm{ab}$ & $4,34 \pm 0,75 a$ & $2,13 \pm 0,22 b$ & $2,10 \pm 0,19 b$ \\
\hline AGPI:AGS3 & 0,21 & $\pm 0,01 \mathrm{a}$ & $0,23 \pm 0,03 a$ & $0,26 \pm 0,01 a$ & $0,22 \pm 0,04 a$ \\
\hline AGMI:AGS4 & 0,86 & $\pm 0,12 \mathrm{a}$ & $0,87 \pm 0,29 a$ & $0,71 \pm 0,03 a$ & $0,61 \pm 0,08 a$ \\
\hline AGD5 & 69,60 & $\pm 2,62 \mathrm{a}$ & $75,41 \pm 2,00 a$ & $69,87 \pm 3,18 \mathrm{a}$ & $67,79 \pm 1,31 \mathrm{a}$ \\
\hline
\end{tabular}

${ }^{1}$ Médias seguidas de letras diferentes nas linhas, diferem $(P<0,05)$ significativamente pelo teste Tukey.

${ }^{2}$ Coeficiente de variação (\%).

3 AGPI - ácidos graxos poliinsaturados; AGS - ácidos graxos saturados.

${ }^{4}$ AGMI - ácidos graxos monoinsaturados.

${ }^{5}$ AGD - ácidos graxos desejáveis = AGMI - AGPI - C18:0. 
ficos dos lipídios encontrados nas carnes vermelhas, com valores de 2,1 a 2,8\% para carne ovina. Considerando a variação apresentada por estes autores, observou-se que os valores da relação (C18:0 + C18:1) : C16:0 neste trabalho foram um pouco acima dos valores reportados, que variaram de 2,10 a 4,34\%. Madruga et al. (2005), avaliando a qualidade da carne de ovinos Santa Inês, reportaram valores da relação (C18:0 + C18:1) : C16:0 variando de 2,53 a 2,76\% e confirmaram a qualidade da fração lipídica de cordeiros Santa Inês. Verificou-se que os animais do grupo controle e do grupo alimentado com a dieta com $20 \%$ de caroço de algodão integral ficaram fora da faixa de variação dos valores da relação (C18:0 + C18:1) : C16:0, diferente dos outros dois grupos, cujas dietas continham 30 e $40 \%$ de caroço de algodão integral, que ficaram dentro dos valores reportados na literatura.

Os valores dos ácidos graxos desejáveis (AGD) variaram de 67,79 a 75,41\%. Avaliando a qualidade da carne de ovinos Santa Inês, Madruga et al. (2005), reportaram valores de AGD variando de 70,27 a 72,48\%. Banskalieva et al. (2000) e Rhee et al. (1992) reportaram médias de ácidos graxos desejáveis (AGD) na carne de ovinos, de 64 a 72\%. Portanto, houve concordância dos resultados dos AGD do trabalho realizado.

A carne dos animais do grupo controle foi a que apresentou melhor qualidade nutricional, por seus altos teores absolutos de ácido oléico (C18:1) e AGMI e baixos teores absolutos de AGS. O grupo dos animais que receberam dieta adicionada de $40 \%$ de CAI, em termos absolutos, apresentou altos níveis de AGS e baixos níveis de ácido oléico (C18:1), comprovando que a utilização do subproduto CAI em um percentual de $40 \%$ poderia diminuir a qualidade da carne de ovinos Santa Inês. No entanto, é necessário que outros experimentos sejam realizados a fim de que esta tendência de elevação do teor de ácidos graxos saturados na carne de ovinos alimentados com percentuais iguais ou superiores a $40 \%$ de caroço de algodão integral seja esclarecida.

\section{Conclusões}

Considerando a composição centesimal, os percentuais de colesterol e fosfolipídios e o perfil de ácidos graxos na carne de ovinos Santa Inês, recomenda-se a utilização de até $40 \%$ de caroço de algodão integral na terminação de ovinos por períodos curtos em confinamento.

\section{Agradecimento}

Ao CNPq eà CAPES, pelo apoio financeiro e pelas bolsas concedidas. À EMEPA/PB, pelo fornecimento dos animais.

\section{Literatura Citada}

ASSOCIATION OF ANALITICAL CHEMISTS - AOAC. Official methods of analysis. 19.ed. Washington, D.C.: 2000. 1219p.

BANSKALIEVA, V.; SAHLU, T.; GOETSCH, A.L. Fatty acid composition of goat muscles and fat depots: a review. Small Ruminant Research, v.37, n.3, p.255-268, 2000.

BARROS, N.N.; VASCONCELOS, V.R.; ARAÚJO, M.R.A. et al. Influência do grupo genético e da alimentação sobre o desempenho de cordeiros em confinamento. Pesquisa Agropecuária Brasileira, v.38, n.9, p.1111-1116, 2003.

BEAUDOIN, A.R. The embriotoxicity of gossypol. Teratology, v.32, p. 251-257, 1985.

BOHAC, C.E.; RHEE, K.S.; ONO, K. Assessment of methodologies for colorimetric cholesterol assay of meats. Journal of Food Science, v.53, p.1642-1693, 1988.

BONAGURIO, S.; PÉREZ, J.R.O.; FURUSHO-GARCIA, I.F. et al. Composição centesimal da carne de cordeiros Santa Inês puros e de seus mestiços com Texel abatidos com diferentes pesos. Revista Brasileira de Zootecnia, v.33, n.6, p.2387-2393, 2004.

BRASIL. MINISTÉRIO DA AGRICULTURA. Regulamento da Inspeção Industrial e Sanitária de Produtos de origem Animal. Brasília: 1997.

BRESSAN, M.C.; ODA, S.N.I.; CARDOSO, M.G. et al. Efeitos dos métodos de abate e sexo na composição centesimal, perfil de ácidos graxos e colesterol da carne de capivaras. Ciência e Tecnologia de Alimentação, v.24, n.2, p.236-242, 2004.

COPPOCK, C.E.; WEST, J.; MOYA, J.R. Effects of a nount of whole cotton whole cottonseed on intake, digestibility and physiological responses of dairy cows. Journal Dairy Science, v.68, n.9, p.2248-2258, 1985.

CORREIA, M.X.C.; COSTA, R.G.; SILVA, J.H.V. et al. Utilização de resíduo agroindustrial de abacaxi desidratado em dietas para caprinos em crescimento: digestibilidade e desempenho. Revista Brasileira de Zootecnia, v.35, n.4, p.1822-1828, 2006.

EGAN, H.; KIRK, R.S.; SAWYER, R. Pearson's chemical analysis of foods. 8.ed. London: Churchill Livingstone, 1981. 591p.

ELY, D.G.; GLENN, B.P.; MAHYUDDIN, M. et al. Drylot versus pasture: early weaned lamb performance to two slaughter weights. Journal of Animal Science, v.48, p.32-37, 1979.

FOLCH, J.; LESS, M.; STANLEY, G.H.S. A simple method for the isolation and purification of lipids from animal tissues. Journal Biological Chemistry, v.226, p.497-509, 1957.

HARRIS, K.B.; CROSS, H.R.; POND, W.G. Effect of dietary fat and cholesterol concentrations of growing pigs selected for high or low serum cholesterol. Journal of Animal Science, v.71, p.807-810, 1993.

JAKOBSEN, K. Dietary modifications of animal fats: status and future perspectives. Fett Lipid, v.101, n.12, p.475-483, 1999.

LOUGH, D.S.; SOLOMON, M.B.; RUMESEY, T.S. et al. Effects of dietary canola seed and soy lecithin in high-forage diets on cholesterol content and fatty acid composition of carcass tissues of growing ram lambs. Journal of Animal Science, v.70, p.1153-1158, 1992.

LOUSADA JR., J.E.; NEIVA, J.N.M.; RODRIGUEZ, N.M. et al. Consumo e digestibilidade de subprodutos do processamento de frutas em ovinos. Revista Brasileira de Zootecnia, v.34, n.2, p.659-669, 2005.

MADRUGA, M.S.; SOUSA, W.H.; ROSALE, M.D. et al. Qualidade da carne de cordeiros Santa Inês Terminados com diferentes dietas. Revista Brasileira de Zootecnia, v.34, n.1, p.309315, 2005.

MADRUGA, M.S.; ARAÚJO, W.O.; SOUSA, W.H. Efeito do genótipo e do sexo sobre a composição química e o perfil de ácidos graxos da carne de cordeiros. Revista Brasileira de Zootecnia, v.35, p.1839-1844, 2006. 
MARQUES, A.V.M.S.; COSTA, R.G.; SILVA, A.M.A. et al. Rendimento, composição tecidual e musculosidade da carcaça de cordeiros Santa Inês alimentados com diferentes níveis de feno de flor-de-seda na dieta. Revista Brasileira de Zootecnia, v.36, n.3, p.610-617, 2007.

MEDEIROS, G.R.; CARVALHO, F.F.R.; FERREIRA, M.A. et al. Efeito dos níveis de concentrado sobre o desempenho de ovinos Morada Nova em confinamento. Revista Brasileira de Zootecnia, v.36, n.4, p.1162-1171, 2007.

MONTEIRO, E.M.; SHIMOKOMAKI, M. Influência do genótipo nos lipídios totais e na fração insaponificável da carne de cordeiros. Ciência Rural, v.25, n.3, p.545-458, 1999.

NATIONAL RESEARCH COUNCIL - NRC. Nutrient requeriments of goats. Angora, dairy and meat in temperate and tropical countries. Washington, D.C: National Academic Press, 1981. 87p.

PEREZ, J.R.O.; BRESSAN, M.C.; BRAGAGNOLO, N. et al. Efeito do peso ao abate de cordeiros Santa Inês e Bergamácia sobre o perfil de ácidos graxos, colesterol e propriedades químicas. Ciência e Tecnologia de Alimentos, v.22, n.1, p.11-18, 2002.

PEREIRA FILHO, J.M.; VIEIRA, E.L. Terminação de ovinos em pastagem: uma abordagem para o semi-árido. Revista SemiÁrido em Foco, v.2, n.1, p.33-55, 2006

RHEE, K.S.; WALDRON, D.F.; ZIPRIN, Y.A. et al. Fatty acid composition of goat diets us intramuscular fat. Meat Science, v.54, p.313-318, 1992.

ROWE, A.; MACEDO, F.A.F.; VISENTAINER, J.V. et al. Muscle composition and fatty acid profile in lambs fattned in dry lot or pasture. Meat Science, v.51, p.283-288, 1999.

ROWE, A. Composição da carne de cordeiros de diferentes grupos genéticos, terminados em pastagens ou confinamento. Maringá: Universidade Estadual de Maringá, 1998. 85p. Dissertação (Mestrado em Zootecnia) - Universidade Estadual de Maringá, 1998.

RUSSO, C.; PREZIUSO, G.; CASAROSA, L. et al. Effect of diet energy source on the chemical-physical characteristics of meat and depot fat of lambs carcasses. Small Ruminant Research, v.33, n.1, p.77-85, 1999.

SILVA SOBRINHO, A.G.S. Aspectos quantitativos e qualitativos da produção de carne ovina. In: A produção animal na visão dos brasileiros. Piracicaba: Fundação de Estudos Agrários Luiz de Queiroz, 2001. p.425-460.

SOLOMON, M.B.; LYNCH, G.P.; LOUGH, D.S. Influence of dietary palm oil supplementation on serum lipid metabolites, carcass characteristics, and lipid composition of carcass tissues of growing ram and lambs. Journal of Animal Science, v.70, p.2746-2751, 1992.

SOUZA, A.A.; ESPÍNDOLA, G.B. Efeito da suplementação com Feno de leucena (Leucaena leucocephala (Lam) de Wit) durante a estação seca sobre o desenvolvimento ponderal de ovinos. Revista Brasileira de Zootecnia, v.28, n.6, p.14241429, 1999.

SOUSA, W.H.; LOBO, R.N.B.; MORAIS, O.R. Ovinos Santa Inês: Estádio de arte e perspectivas. In: SIMPÓSIO INTERNACIONAL SOBRE CAPRINOS E OVINOS DE CORTE, 2.; SIMPÓSIO INTERNACIONAL SOBRE O AGRONEGÓCIO DA CAPRINOCULTURA LEITEIRA, 1., 2003, João Pessoa. Anais... João Pessoa: Emepa, 2003.

STATISTICAL ANALYSIS SYSTEM - SAS. User's guide to statistics. Versão 6.12. Cary: SAS Institute, 1996. 956p.

TSHABALALA, P.A.; STRYDOM, P.E.; WEBB, E.C. et al. Meat quality of designated South African Indigenous goat and sheep breeds. Meat Science, v.65, p.563-570, 2005.

WOOD, J.D.; RICHARDSON, R.L.; NUTE, G.R. et al. Effects of fatty acids on meat quality: a review. Meat Science, v.66, p.21-32, 2003.

WOOD, J.D.; ENSER, M.; FISHER, A.V. et al. Manipulating meat quality and composition. Proceedings of the Nutrition Society, v.58, p.363-370, 1999.

ZAPATA, J.F.F.; NOGUEIRA, C.M.; SEABRA, L.M.A.J. et al. Composição centesimal e lipídica da carne de ovinos do Nordeste Brasileiro. Ciência Rural, v.31, n.4, p.691-695, 2001.

ZEOLA, N.M.B.L.; SILVA SOBRINHO, A.G.; GONZAGA NETO, S. et al. Composição centesimal da carne de cordeiros submetidos a dietas com diferentes teores de concentrado. Ciência Rural, v.34, n.1, p.253-257, 2004

ZUNDT, M.; MACEDO, F.A.F.; MARTINS, E.N. et al. Desempenho de cordeiros alimentados com diferentes níveis protéicos. Revista Brasileira de Zootecnia, v.31, n.3, p.1307-1314, 2002. 